\title{
CARACTERÍSTICAS ACÚSTICAS DA VOGAL ÁTONA FINAL
}

\author{
Fernanda Peres Lopes ${ }^{25}$ \\ Maria José Blaskovski Vieira ${ }^{26}$
}

RESUMO: Este artigo tem como objetivo descrever acusticamente as vogais postônicas finais no falar pelotense. No Brasil, são poucos os estudos que se voltam para a caracterização acústica das postônicas finais. Entre eles, encontram-se os trabalhos de Moraes et al (2002[1992]), Meneses (2012, 2016) e Quintanilha-Azevedo (2016). A amostra sob análise é constituída por 8 informantes da cidade de Pelotas/RS (4 homens e 4 mulheres), de dois níveis de escolaridade e idades entre 18 e 50 anos. Foram analisadas as vogais postônicas finais, levando-se em conta sua duração e os valores de F1 e F2. A análise indicou que as vogais altas tendem a abaixar enquanto a vogal baixa tende a elevar-se. Além disso, percebeu-se uma centralização da vogal alta posterior. Em relação à duração da postônica, verificou-se que homens de baixa escolaridade produzem as postônicas de forma significativamente mais longa do que homens de alta escolaridade. No grupo das mulheres, houve diferença significativa somente no que diz respeito à duração da vogal baixa.

Palavras-chave: vogais postônicas; descrição acústica; valores de F1 e F2; duração da vogal.

ABSTRACT: This article aims to acoustically describe the final postonic vowels in the Portuguese spoken in the city of Pelotas. In Brazil, few studies have turned to the acoustic characterization of the final postonics. Among them, there are the studies by Moraes et al (2002 [1992]), Meneses (2012, 2016) and Quintanilha-Azevedo (2016). The sample under analysis consists of 8 informants from the city of Pelotas / RS (4 males and 4 females), with two educational backgrounds and ages between 18 and 50 years. The final postonic vowels were analyzed, taking into account their duration and the values of F1 and F2. The analysis

${ }^{25}$ Mestre em Linguística pela Universidade Federal de Pelotas-UFPEL. Professora da rede municipal de ensino-Pelotas.

${ }^{26}$ Doutora em Linguística e Letras pela Pontifícia Universidade Católica do Rio Grande do Sul-PUC/RS. Professora adjunta na Faculdade de Letras da Universidade Federal de Pelotas-UFPel. 
70 | Fernanda Peres Lopes e Maria José Blaskovski Vieira

indicated that the high vowels tend to lower as the low vowel tends to rise. In addition, a centralization of the posterior high vowel was noted. Regarding the duration of the postonics, it was verified that men of low schooling produce postonics significantly longer than men of high schooling. In the group of women, there was significant difference only with regard to the duration of the low vowel.

Keywords - postonic vowels; acoustic description; F1 and F2 values; vowel duration.

\section{Introdução}

O presente trabalho tem como objetivo descrever acusticamente as vogais átonas finais presentes no falar pelotense. São poucos os estudos que se voltam para a caracterização acústica das postônicas no português brasileiro. Entre eles, encontram-se os estudos de Moraes et al (2002[1992]); Meneses (2012 e 2016) e Quintanilha-Azevedo (2016) que mostram que as vogais átonas finais tendem a ter menor duração, em comparação com as vogais da posição tônica; a apresentar maior dispersão e centralização dos valores de F1 e F2, também em relação à tônica; e a ser desvozeada e apagada em contextos determinados.

Em trabalho sobre o sistema vocálico do português do Brasil, Moraes et al. (2002 [1992]) caracterizam acusticamente as vogais orais tônicas, pretônicas e postônicas dos dialetos falados em cinco capitais Porto Alegre, São Paulo, Rio de Janeiro, Salvador e Recife - por meio dos valores do primeiro (F1) e segundo (F2) formantes. Os autores coletaram amostras de vogais de um corpus de fala espontânea, composto por entrevistas de quinze locutores com formação universitária (três de cada área urbana), estratificados por três faixas etárias (25-35 anos, 36-56 anos e 56 anos em diante). Para cada falante, foram medidas quinze ocorrências de cada vogal em cada posição tônica, totalizando 1575 vogais tônicas, 1395 vogais pretônicas e 675 vogais postônicas.

A análise indicou que Salvador apresenta um comportamento sistemático com relação às vogais átonas finais. É o dialeto em que a pronúncia das vogais finais é sempre a menos baixa. Porto Alegre e Recife abaixam apenas as vogais altas e, muito pouco, a vogal baixa; e Rio de Janeiro e São Paulo têm um percentual médio de abaixamento das vogais altas, apresentando um comportamento oposto em relação à vogal baixa.

Os autores concluem que, em relação às vogais que possuem o traço [-bx], o processo de atomização se dá na dimensão de F2, ou seja, no 
eixo horizontal (ant. x post.). No eixo vertical (grau de elevação, F1), não se verificam, praticamente, diferenciações: [i] e [u], tanto tônicos como átonos, têm praticamente a mesma altura. Para a vogal [a] dá-se o inverso, já que a diferenciação é no grau de abertura (F1). De acordo com Moraes et al. (2002 [1992])"o processo de atomização centraliza as vogais altas e eleva a vogal baixa. Esse processo pode ser explicado como decorrente da menor duração observada nas vogais átonas”.

Dias e Seara (2013) analisaram acusticamente a redução e o apagamento de vogais átonas finais a partir de dados de fala da região metropolitana de Florianópolis/Santa Catarina. Participaram da pesquisa 3 indivíduos do sexo feminino -2 crianças e 1 adulto.

Investigaram-se os efeitos da tonicidade e da idade sobre duração e frequências formânticas (F1 e F2) das vogais tônicas ([i, $\alpha, u]$ ) e átonas finais $([I, \mathfrak{e}, \mho])$. Na comparação das vogais tônicas com as átonas finais, os resultados mostram semelhanças entre os grupos: vogais átonas finais apresentam menor duração e redução do espaço acústico e o apagamento vocálico ocorre predominantemente diante de consoantes surdas e com vogais altas.

Meneses (2012) analisou, do ponto de vista acústico-articulatório, as vogais [a], [i] e [u] precedidas de consoante fricativa alveolar surda, em contexto tônico e átono final. Participaram da pesquisa 6 mulheres naturais de Vitória da Conquista/Bahia, todas elas universitárias e com a mesma faixa etária - 20 a 30 anos. Na análise, o autor identificou vogais completamente desvozeadas, apresentando uma porção aperiódica, sem pulso glótico e com configuração formântica indefinida. Em função de tal configuração, não houve condições de medição acústicas de duração.

Meneses (2016) investiga dois processos de redução do Português Brasileiro: o desvozeamento das vogais altas finais e a elisão no sândi vocálico externo. Em relação ao primeiro processo, busca mostrar que há um processo de variação sincrônica na produção das vogais pós-tônicas finais do $\mathrm{PB}$, que se inicia na redução e se completa com o seu desvozeamento total. Dados acústicos e aerodinâmicos atestam resultados anteriores (MENESES, 2012), de acordo com os quais, no desvozeamento, a vogal final que parece apagada está apenas radicalmente reduzida e quase inteiramente sobreposta à consoante precedente.

Em seu trabalho sobre a epêntese vocálica em variedades do português, Quintanilha-Azevedo (2016) realizou investigação acústica a respeito de vogais do português brasileiro (PB) e do português Europeu (PE). Tal investigação tinha por objetivo analisar as frequências formânticas das vogais em posições extremas comparando-as com a vogal 
epentética sonora, inserida para reparar estruturas silábicas impróprias no português.

O estudo realizado contou com a participação de oito informantes monolíngues brasileiros de Pelotas/RS e oito informantes monolíngues portugueses de Lisboa, com idades entre 22 e 34 anos e com nível de escolaridade superior completo ou incompleto.

A investigação acústica realizada por Quintanilha-Azevedo (2016) mostra que as vogais que ocorrem em posição átona final no português brasileiro são [e, I, v]. $\mathrm{O}[\boldsymbol{e}]$ apresenta $\mathrm{F} 1$ mais baixo do que o [a] em posição tônica, revelando que esta vogal é mais alta, além disso, também apresenta F2 mais baixo se comparada ao [a] tônico, demonstrando ser mais posterior; o [I] apresenta F1 mais alto do que o [i] tônico, demonstrando ser mais baixo, e valor de F2 menor, demonstrando ser mais central; e o [u] apresenta valor de F1 mais alto do que o [u] tônico, ou seja, é mais baixo, e mais central ou menos posterior.

Para atender aos objetivos a que se propõe, este artigo está estruturado da seguinte forma: após esta introdução, são descritos os princípios metodológicos utilizados na coleta e análise dos dados. $\mathrm{Na}$ seção seguinte, são apresentados e discutidos os resultados obtidos. Por fim, são apresentadas as conclusões, seguidas das referências bibliográficas.

\section{Metodologia}

Para participação deste estudo, foram selecionados 4 homens e 4 mulheres de acordo com a escolaridade. Foram considerados dois níveis de escolaridade: sujeitos com até 6 anos de escolaridade e sujeitos com, no mínimo, 9 anos de escolaridade.

O corpus utilizado foi formado a partir da leitura de frase-veículo do tipo "Digo ____ de novo", contendo palavras com as vogais [a], [i] e [u] na posição postônica final. Para cada uma das vogais, foram selecionadas 24 palavras, levando-se em conta o contexto precedente à postônica e a frequência das palavras.

Os 72 vocábulos que formaram o corpus são substantivos, paroxítonos e trissílabos, com a sílaba postônica apresentando padrão CV. Os vocábulos foram escolhidos de modo a contemplar os seguintes contextos linguísticos precedentes: plosivas [p], [t], [k] e fricativas [s], [f], [S]. Também foi feito o controle do contexto seguinte, para o qual foram escolhidos vocábulos iniciados por oclusiva desvozeada - [p], [t] ou $[\mathrm{k}]$ - ou 
por fricativa desvozeada - [f], [s] ou [S] - e que tivessem coerência semântica com o vocábulo em análise.

Para cada contexto precedente foram escolhidas duas palavras de alta frequência ${ }^{27}$ e duas de baixa frequência, sendo consideradas de alta frequência palavras que têm acima de $1 \%$ de ocorrência por milhão e, de baixa frequência, as palavras com menos de $1 \%$ de ocorrência. A seleção dessas palavras foi feita com o auxílio de um buscador fonológico, vinculado ao Projeto ASPA (Avaliação Sonora do Português Atual) ${ }^{28}$, disponível em http://www.projetoaspa.org. Definidas as palavras, foram levantadas as suas frequências de ocorrência no Corpus Brasileiro ${ }^{29}$, disponível em www.sketchengine.co.uk.

A coleta dos dados foi realizada entre março e novembro de 2016. As gravações foram realizadas, em parte, na cabine acústica do Laboratório Emergência da Linguagem Oral - LELO, da Universidade Federal de Pelotas e, nos casos de impossibilidade de deslocamento do informante, as gravações foram realizadas em uma sala isolada. Em cada sessão de coleta foi realizada a leitura das frases-veículo, apresentadas aleatoriamente na tela de um computador. Cada frase foi lida três vezes pelo informante. Os equipamentos utilizados foram um notebook HP G42-413BR e um gravador digital, modelo Zoom H4n.

Os dados foram submetidos à análise acústica, com a utilização do software Praat versão 6.0.19 (BOERSMA \& WEENINK, 2007). As vogais foram segmentadas a partir da observação, no espectrograma de banda larga, do formato de onda e da configuração dos formantes. Em seguida, foram feitas medições, com base nos seguintes parâmetros acústicos: duração absoluta da vogal; duração relativa, que consiste no percentual ocupado pela vogal no interior da palavra e frequência.

${ }^{27}$ Neste estudo, não serão apresentados os resultados que dizem respeito à frequência das palavras.

${ }^{28}$ O Projeto ASPA é um empreendimento conjunto entre pesquisadores que atuam em áreas diversas do conhecimento e que necessitam de um conhecimento sólido da organização sonora do português contemporâneo.

${ }^{29}$ O projeto Corpus Brasileiro, do Grupo de Estudos de Linguistica de Corpus (GELC), da PUCSP, visa a construir e disponibilizar online o Corpus Brasileiro, composto por um bilhão de palavras de português brasileiro contemporâneo. 
A marcação da duração absoluta, em milissegundos (ms), foi obtida selecionando-se, à esquerda, o primeiro ciclo estável e, à direita, o último ciclo estável da vogal analisada. E a duração relativa foi obtida por meio do software Excel, em que foi calculado, com base nos valores de duração absoluta da palavra e da vogal, o percentual de ocupação da vogal na palavra.

Os valores de F1 e F2 foram extraídos a partir do ponto central da vogal que oferece menor influência das consoantes vizinhas, distante das faixas de transição consoante-vogal e vogal-consoante (início e final da vogal). O software Praat gera automaticamente os valores de formantes. Barbosa (2015, p.265) afirma, no entanto, que as vogais postônicas altas, por terem duração muito curta, não apresentam um padrão formântico estacionário, diferentemente da vogal baixa, que é mais longa que as altas e que pode apresentar em seu ponto médio padrões formânticos mais estáveis. Considerando que cada vocábulo foi produzido três vezes por cada informante, depois de terem sido levantados todos os valores para os parâmetros aqui controlados, foram calculadas as médias referentes à duração relativa e absoluta da vogal e as médias para cada formante ( $\mathrm{F} 1 \mathrm{e}$ F2).

Buscando verificar se as diferenças encontradas entre os dados dos sujeitos desta pesquisa, no que diz respeito aos parâmetros controlados, eram estatisticamente significativas, procedeu-se à análise estatística que utilizou como ferramenta o software de análise SPSS STATISTICS, versão 17.0. Esse software possibilitou a execução de testes com o objetivo de realizar comparações entre grupos e entre informantes. Os resultados obtidos levaram em conta a medição de todos os itens lexicais produzidos, permitindo que se fizessem afirmações confiáveis do ponto de vista estatístico a respeito dos parâmetros controlados.

\section{Resultados}

Neste estudo, foram analisados acusticamente 1448 dados referentes às vogais átonas [a, i, u], sendo 726 realizados pelos homens e 722 realizados pelas mulheres. Após a execução de testes de normalidade, foi verificada a anormalidade da amostra, o que conduziu à execução de testes não-paramétricos. Selecionou-se, em função disso, o teste de MannWhitney, com valor de $p$ estabelecido em 0,05. A seguir, serão apresentados os resultados relacionados à análise intergrupos, levando em conta a escolaridade. Inicia-se com resultados referentes ao grupo dos homens. 
Quadro 1: Produção das vogais em função da escolaridade - homens

\begin{tabular}{|c|c|c|c|c|c|}
\hline \multicolumn{2}{|l|}{ Escolaridade } & \multirow{2}{*}{$\frac{\mathrm{N}}{116}$} & \multirow{2}{*}{$\begin{array}{l}\text { Média } \\
69,2759\end{array}$} & \multirow{2}{*}{$\begin{array}{l}\begin{array}{l}\text { Desvio } \\
\text { Padrão }\end{array} \\
18,52077\end{array}$} & \multirow{2}{*}{$\begin{array}{c}\begin{array}{c}\text { Std. Error } \\
\text { Mean }\end{array} \\
1,71961\end{array}$} \\
\hline Duração de [a] & Baixa & & & & \\
\hline & Alta & 142 & 42,5493 & 11,01744 & ,92456 \\
\hline \multirow[t]{2}{*}{ F1 de [a] } & Baixa & 116 & 459,3540 & 67,31616 & 6,25015 \\
\hline & Alta & 141 & 468,6439 & 47,06577 & 3,96365 \\
\hline \multirow[t]{2}{*}{ F2 de [a] } & Baixa & 116 & 1498,0448 & 231,15919 & 21,46259 \\
\hline & Alta & 141 & 1427,2016 & 238,49866 & 20,08521 \\
\hline \multirow[t]{2}{*}{ Duração de [i] } & Baixa & 40 & 70,4000 & 24,42235 & 3,86151 \\
\hline & Alta & 82 & 36,5366 & 12,66881 & 1,39904 \\
\hline \multirow[t]{2}{*}{ F1 de [i] } & Baixa & 37 & 327,1038 & 41,20656 & 6,77432 \\
\hline & Alta & 76 & 364,5059 & 62,31949 & 7,14854 \\
\hline \multirow[t]{2}{*}{ F2 de [i] } & Baixa & 37 & 1920,1603 & 171,17581 & 28,14113 \\
\hline & Alta & 76 & 1952,8700 & 186,34903 & 21,37570 \\
\hline \multirow[t]{2}{*}{ Duração de [u] } & Baixa & 56 & 57,8929 & 21,64900 & 2,89297 \\
\hline & Alta & 99 & 38,4747 & 14,28525 & 1,43572 \\
\hline \multirow[t]{2}{*}{ F1 de $[u]$} & Baixa & 51 & 342,2035 & 64,66205 & 9,05450 \\
\hline & Alta & 84 & 431,1960 & 59,66252 & 6,50971 \\
\hline \multirow[t]{2}{*}{ F2 de $[u]$} & Baixa & 51 & 1363,7467 & 306,95894 & 42,98285 \\
\hline & Alta & 84 & 1472,3767 & 372,56950 & 40,65066 \\
\hline
\end{tabular}


76 | Fernanda Peres Lopes e Maria José Blaskovski Vieira

Quadro 2: Teste de Mann-Whitney - diferenças entre alta e baixa escolaridade (homens)*

\begin{tabular}{|c|c|c|c|c|c|c|c|c|c|}
\hline & $\begin{array}{c}\text { Duração } \\
\text { de [a] }\end{array}$ & F1 de [a] & F2 de [a] & $\begin{array}{c}\text { Duração } \\
\text { de [i] }\end{array}$ & F1 de [i] & F2 de [i] & $\begin{array}{c}\text { Duração } \\
\text { de [u] }\end{array}$ & F1 de [u] & F2 de [u] \\
\hline $\begin{array}{c}\text { Mann } \\
\text { Whitney } \\
\text { U }\end{array}$ \\
$\begin{array}{c}\text { Wilcoxon } \\
\text { W }\end{array}$ & 1382,500 & 7203,000 & 6523,000 & 372,500 & 887,000 & 1210,500 & 1229,000 & 701,000 & 1862,000 \\
Z & 11535,500 & 13989,000 & 16534,000 & 3775,500 & 1590,000 & 1913,500 & 6179,000 & 2027,000 & 3188,000 \\
$\begin{array}{c}\text { Asymp. } \\
\text { Sig. (2. } \\
\text { tailed) }\end{array}$ & $, 11,497$ & $-1,644$ & $-2,791$ & $-6,916$ & $-3,175$ & $-1,196$ & $-5,749$ & $-6,540$ & $-1,271$ \\
\hline
\end{tabular}

a. Grouping Variable: Escolaridade

Com relação ao grupo dos homens, o teste de Mann-Whitney verificou diferenças estatisticamente relevantes $(p<0,05)$ entre alta $e$ baixa escolaridade na produção das três vogais investigadas, [a], [i] e [u], conforme mostra o Quadro 2. Na vogal [a], percebeu-se que os informantes de baixa escolaridade apresentaram vogais significativamente mais longas $(Z=-11,497 ; p=0,000)$ e com F2 mais alto $(Z=-2,791 ; p=$ $0,005)$. No caso de [i], os informantes com baixa escolaridade igualmente revelaram vogais mais longas $(Z=-6,916 ; p=0,000)$, enquanto aqueles com alta escolaridade demonstraram maior $F 1 \quad(Z=-3,175 ; p=0,001)$. Finalmente, na produção da vogal [u], novamente os informantes de baixa escolaridade revelaram produções com maior duração $(Z=-5,749$; $p=$ $0,000)$ e os informantes de alta escolaridade revelaram produções de F1 mais altas $(Z=6,540 ; p=0,000)$. O Quadro 1 sintetiza a análise estatística descritiva no grupo dos homens.

Comparando-se os valores de F1 e F2 com aqueles encontrados no estudo de Moraes et ali (2002 [1972]) para as postônicas produzidas por sujeitos de Porto Alegre e com os valores encontrados por QuintanilhaAzevedo (2016) para sujeitos de Pelotas, percebem-se algumas diferenças e semelhanças. Nesta amostra, a vogal [a] é mais alta se comparada à do falar de Porto Alegre, apresentando uma média de F1 para os quatro sujeitos de $463 \mathrm{~Hz}$ (verifica-se pouca diferença entre os valores individuais), sendo também alta em relação aos valores apresentados por Quintanilha-Azevedo (592 Hz). No estudo de Moraes et ali (op. cit), a 
média de F1 encontrada é de $539 \mathrm{~Hz}$ e no estudo de Quintanilha-Azevedo é de $592 \mathrm{~Hz}$. Ao serem observados os valores de F1 na posição tônica, encontrados por Escudero et al $\left(2009^{30}\right)$, por Moraes et ali e por Quintanilha-Azevedo, é possível perceber que o valor médio de F1 obtido neste estudo para a vogal [a] aproxima-se do valor de $[\varepsilon]$, indicando que a vogal [a] eleva-se no espaço acústico.

Em relação aos valores de F2 apresentados pelos sujeitos desta pesquisa, também são observadas semelhanças ao ser estabelecida comparação com os dados apresentados por Moraes et ali e por Quintanilha-Azevedo. Tanto separadamente quanto estabelecendo médias, os valores de F2 dos sujeitos (apesar de haver diferenças bastante grandes entre os valores de cada sujeito pesquisado), apresentam uma anteriorização da vogal [a]. Essa anteriorização também foi constata por Moraes et ali, no entanto, ela é menor nos dados que aqui são apresentados: $1462 \mathrm{~Hz}$, enquanto Quintanilha-Azevedo e Moraes et ali expõem dados com médias de $1407 \mathrm{~Hz}$ e $1578 \mathrm{~Hz}$, respectivamente. Se o valor médio de F2 for comparado aos valores de F2 encontrados por Escudero et al (op.cit) e por Moraes et ali para a posição tônica, percebe-se novamente a aproximação com os valores de F2 que caracterizam a vogal $[\varepsilon]$.

Para a vogal [i], os valores de $\mathrm{F} 1$ obtidos são similares àqueles encontrados por Quintanilha-Azevedo e por Moraes et ali. A média neste estudo foi de $330 \mathrm{~Hz}$ enquanto que em Quintanilha-Azevedo foi de 334 $\mathrm{Hz}$ e em Moraes a média foi de $394 \mathrm{~Hz}$. Para os três estudos, os valores indicam um abaixamento da vogal [i] na posição postônica (maior no falar de Porto Alegre), em comparação com os valores para a posição tônica. $\mathrm{O}$ valor médio de $\mathrm{F} 1$ dos dados desta pesquisa $(330 \mathrm{~Hz})$ se aproxima do valor de F1 que caracteriza a vogal [e] nos dados de Escudero et al (357 $\mathrm{Hz}$ ).

Já em relação aos valores de F2 para a vogal [i], verifica-se similaridade com o encontrado por Moraes et ali e por QuintanilhaAzevedo. Neste estudo, a média de F2 foi de $1976 \mathrm{~Hz}$, em QuintanilhaAzevedo foi de $1949 \mathrm{~Hz}$ e, em Moraes et ali, de $2050 \mathrm{~Hz}$. Fazendo a comparação com valores para a posição tônica, percebe-se que F2 de 1976

30 Tendo em vista que não foram levantados os valores de F1 e F2 das vogais [a], [i] e [u] na posição tônica, optou-se por tomar como referência os valores dos formantes nessa posição apresentados em Escudero et al (2009). 
78 | Fernanda Peres Lopes e Maria José Blaskovski Vieira

$\mathrm{Hz}$ é um valor intermediário entre o valor de [e] e de $[\varepsilon]$, indicando a centralização a vogal [i] na comunidade em estudo.

Para a vogal $[\mathrm{u}]$, o valor médio de F1 obtido a partir dos dados analisados foi de $378 \mathrm{~Hz}$, o mesmo valor encontrado em QuintanilhaAzevedo e valor semelhante ao encontrado por Moraes et ali $(387 \mathrm{~Hz})$. Tais valores indicam abaixamento da vogal, que se manifesta de forma mais forte nos valores apresentados pelos sujeitos L $(438 \mathrm{~Hz})$ e P $(389 \mathrm{~Hz})$, e aproximam os valores aqui encontrados com aqueles que caracterizam a vogal [o] da posição tônica, conforme se verifica em Escudero et al.

Quanto ao valor médio de F2 para a vogal [u] - $1430 \mathrm{~Hz}$, diferencia-se de forma notável daquele obtido por Moraes et ali $(971 \mathrm{~Hz})$ e por Quintanilha-Azevedo $(1022 \mathrm{~Hz})$ indicando, neste estudo, a ocorrência de uma forte centralização dessa vogal.

Com base na média de F1 e F2 de cada informante foram criados gráficos a partir do script de Ricardo Bion.

Figura 1: Valores médios de F1 e F2 (em $\mathrm{Hz})$ de quatro informantes homens

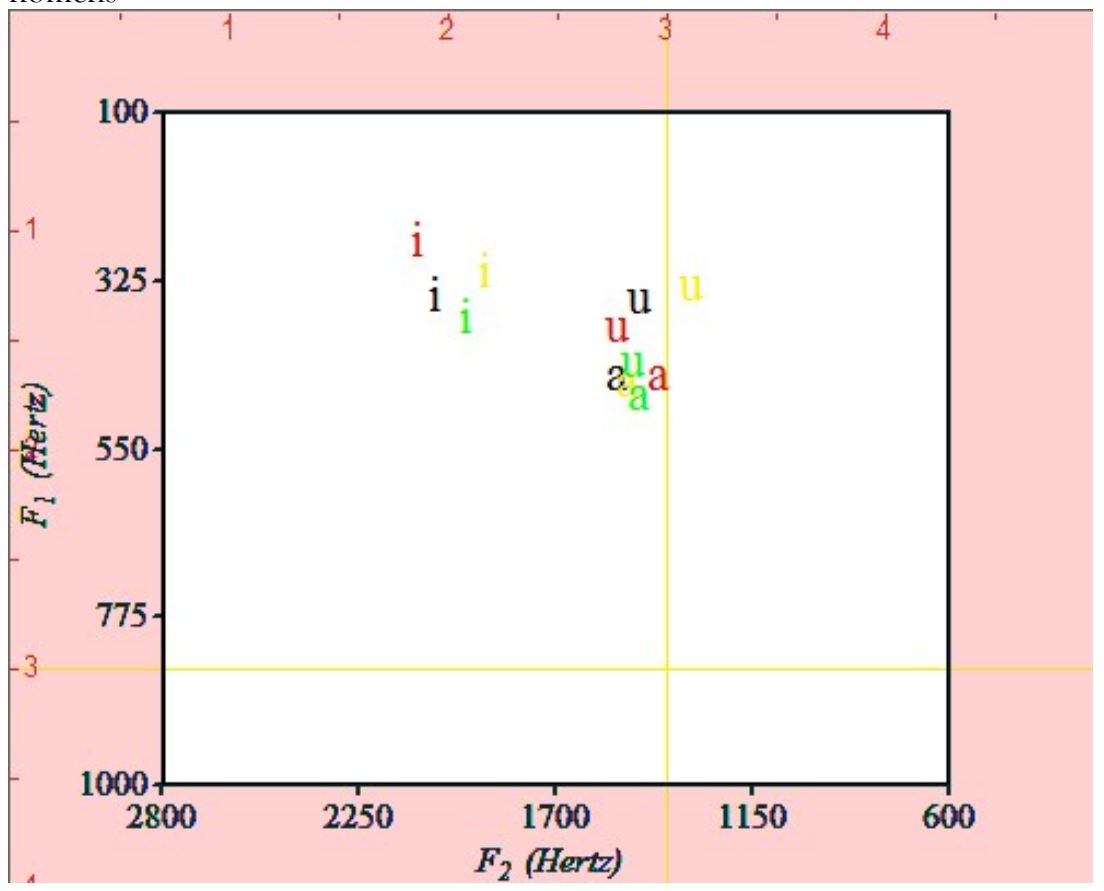


Características acústicas da vogal átona final | 79

A seguir são apresentados os resultados referentes ao grupo das mulheres.

Quadro 3: Produção das vogais em função da escolaridade - mulheres

\begin{tabular}{|ll|r|r|r|r|}
\hline & Escolaridade & \multicolumn{1}{c|}{$\mathrm{N}$} & \multicolumn{1}{c|}{ Média } & Desvio Padrão & Std. Error Mean \\
\hline Duração de [a] & Baixa & 101 & 45,0198 & 12,16304 & 1,21027 \\
& Alta & 142 & 48,6972 & 12,09243 & 1,01477 \\
\hline F1 de [a] & Baixa & 98 & 512,0421 & 71,70928 & 7,24373 \\
& Alta & 142 & 556,4880 & 51,91230 & 4,35638 \\
\hline F2 de [a] & Baixa & 98 & 1617,8038 & 222,61948 & 22,48796 \\
& Alta & 142 & 1589,0833 & 262,57843 & 22,03509 \\
\hline F1 de [i] & Baixa & 22 & 370,3923 & 67,60891 & 14,41427 \\
& Alta & 65 & 398,8434 & 63,30382 & 7,85187 \\
\hline F2 de [i] & Baixa & 22 & 2110,7814 & 236,59274 & 50,44174 \\
& Alta & 65 & 2161,9655 & 215,41777 & 26,71929 \\
\hline Duração de [u] & Baixa & 26 & 41,1154 & 16,27348 & 3,19149 \\
& Alta & 96 & 45,1354 & 19,09457 & 1,94883 \\
\hline F1 de [u] & Baixa & 24 & 397,6525 & 55,66669 & 11,36292 \\
& Alta & 89 & 447,3169 & 63,71813 & 6,75411 \\
\hline F2 de [u] & Baixa & 24 & 1639,4333 & 363,88691 & 74,27810 \\
& Alta & 89 & 1453,9893 & 337,08650 & 35,73110 \\
\hline
\end{tabular}


80 | Fernanda Peres Lopes e Maria José Blaskovski Vieira

Quadro 4: Teste de Mann. Whitney - diferenças entre alta e baixa escolaridade (mulheres)"

\begin{tabular}{|c|c|c|c|c|c|c|c|c|c|}
\hline & $\begin{array}{c}\text { Duração de } \\
\text { [a] }\end{array}$ & F1 de [a] & F2 de [a] & $\begin{array}{c}\text { Duração } \\
\text { de [i] }\end{array}$ & F1 de [i] & F2 de [i] & $\begin{array}{c}\text { Duração } \\
\text { de [u] }\end{array}$ & $\begin{array}{c}\text { F1 de } \\
{[\mathrm{u}]}\end{array}$ & F2 de [u] \\
\hline $\begin{array}{c}\text { Mann- } \\
\text { Whitney U }\end{array}$ & 5729,500 & 3940,500 & 6152,000 & 638,000 & 575,000 & 601,000 & 1083,500 & 508,000 & 734,000 \\
Wilcoxon W & 10880,500 & 8791,500 & 16305,000 & 3194,000 & 828,000 & 854,000 & 1434,500 & 808,000 & 4739,000 \\
Z & $-2,671$ & $-5,708$ & $-1,525$ & $-1,834$ & $-1,367$ & $-1,113$ & $-1,029$ & $-3,931$ & $-2,345$ \\
$\begin{array}{c}\text { Asymp. Sig. } \\
\text { (2-tailed) }\end{array}$ &, 008 &, 000 &, 127 &, 067 &, 172 &, 266 &, 304 &, 000 &, 019 \\
\hline
\end{tabular}

a. Grouping Variable: Escolaridade

Da mesma forma que para o grupo dos homens, foram estabelecidas comparações entre as mulheres com baixa e alta escolaridade quanto aos valores de duração absoluta, F1 e F2 das vogais [a], [i] e [u]. Por meio do teste de Mann-Whitney, foram verificadas diferenças estatisticamente relevantes na produção das vogais [a] e [u], conforme pode ser observado no Quadro 4. No que se refere à vogal [a], pode-se perceber que os participantes com alta escolaridade produziram vogais significativamente mais longas $(Z=-2,671 ; p=0,08)$ e com F1 mais elevado $(Z=-5,708 ; p=0,000)$ do que os informantes de baixa escolaridade. Quanto à vogal [u], os informantes com alta escolaridade apresentaram F1 significativamente mais elevado $(Z=-3,931 ; p=0,000)$, enquanto os informantes com baixa escolaridade revelaram $F 2$ mais elevado $(Z=-2,345$; $p=0,019)$.

Com relação aos formantes extraídos dos dados do grupo das mulheres, observa-se, no Quadro 3, para a vogal [a], valores que variam entre $562 \mathrm{~Hz}$, nos dados de $\mathrm{E}$, e $506 \mathrm{~Hz}$, nos dados de C. A média de F1 encontrada entre as quatro informantes mulheres foi de $533 \mathrm{~Hz}$ para essa vogal, valor semelhante ao encontrado por Dias e Seara (2013) em dados de Florianópolis $(528 \mathrm{~Hz})$. Comparando-se esse valor médio de F1 com os valores encontrados por Escudero et al, para a posição tônica $(910 \mathrm{~Hz})$, percebe-se uma significativa elevação da vogal produzida no falar de Pelotas, a exemplo do que fora constatado nos dados dos homens desta pesquisa.

No que diz respeito a F2 da vogal [a], os valores variam entre 1666 $\mathrm{Hz}$, nos dados de $\mathrm{M}$, e $1557 \mathrm{~Hz}$, nos dados de J. A média encontrada foi de $1600 \mathrm{~Hz}$, valor próximo ao encontrado por Dias e Seara $(1578 \mathrm{~Hz})$ e próximo também ao encontrado por Escudero et al para [a] da posição 
tônica. Observa-se aqui uma diferença em relação aos homens que tenderam a anteriorizar a vogal.

Para a vogal [i], constata-se maior variação nos valores de F1. O menor valor é de $348 \mathrm{~Hz}$, nos dados de $\mathrm{C}$, e o maior é de $443 \mathrm{~Hz}$, nos dados de E. A média encontrada para essa vogal foi de $390 \mathrm{~Hz}$, valor superior ao encontrado por Dias e Seara (op.cit) - $346 \mathrm{~Hz}$. Tanto o valor médio de F1 quanto das produções individuais revelam um abaixamento da vogal [i], quando se comparam os valores obtidos neste trabalho com valores de F1 da vogal [i] tônica. Nessa posição, Escudero et al encontraram valor médio de $307 \mathrm{~Hz}$. Semelhante abaixamento de [a] também foi constatado nos dados dos falantes masculinos.

Em relação a F2, foram obtidos valores entre $2308 \mathrm{~Hz}$ e $1973 \mathrm{~Hz}$ nos dados de $\mathrm{M}$ e C, respectivamente. O valor médio de F2 foi de 2151 $\mathrm{Hz}$, superior ao encontrado por Dias e Seara $(2408 \mathrm{~Hz})$. Comparando-se o valor médio aqui obtido com o encontrado em Escudero et al para a vogal [i] tônica $(2676 \mathrm{~Hz})$, observa-se uma grande diferença nos valores, indicando que na posição postônica a vogal [i] centraliza-se e tem valor próximo ao da vogal $[\varepsilon]$ tônica.

Como pode ser visto no Quadro 3, para a vogal [u], os valores de F1 encontrados variam entre $390 \mathrm{~Hz}$ (informante C) e $463 \mathrm{~Hz}$ (informante E), sendo a média $427 \mathrm{~Hz}$. Esses valores são superiores aos verificados por Dias e Seara na fala da informante de Florianópolis (370 $\mathrm{Hz}$ ) e sugerem que a vogal $[\mathrm{u}]$ sofre um abaixamento na comunidade em estudo. Nos dados dos homens deste estudo, também constatou-se o abaixamento dessa vogal.

Por fim, os valores de F2 para a vogal [u], encontrados neste estudo, mostram-se bastante variáveis entre as mulheres: de $1744 \mathrm{~Hz}$ (dados de M) a $1343 \mathrm{~Hz}$ (dados de J). A média para essa vogal foi de 1572 $\mathrm{Hz}$, indicando que a vogal produzida é fortemente anteriorizada, ocupando uma porção central no espaço acústico. $\mathrm{O}$ valor médio para F2 obtido neste estudo é superior ao encontrado por Dias e Seara e aproxima-se dos valores encontrados por Escudero et al para a vogal [a] tônica. 
82 | Fernanda Peres Lopes e Maria José Blaskovski Vieira

Figura 2: Valores médios de F1 e F2 (em $\mathrm{Hz}$ ) de quatro informantes mulheres

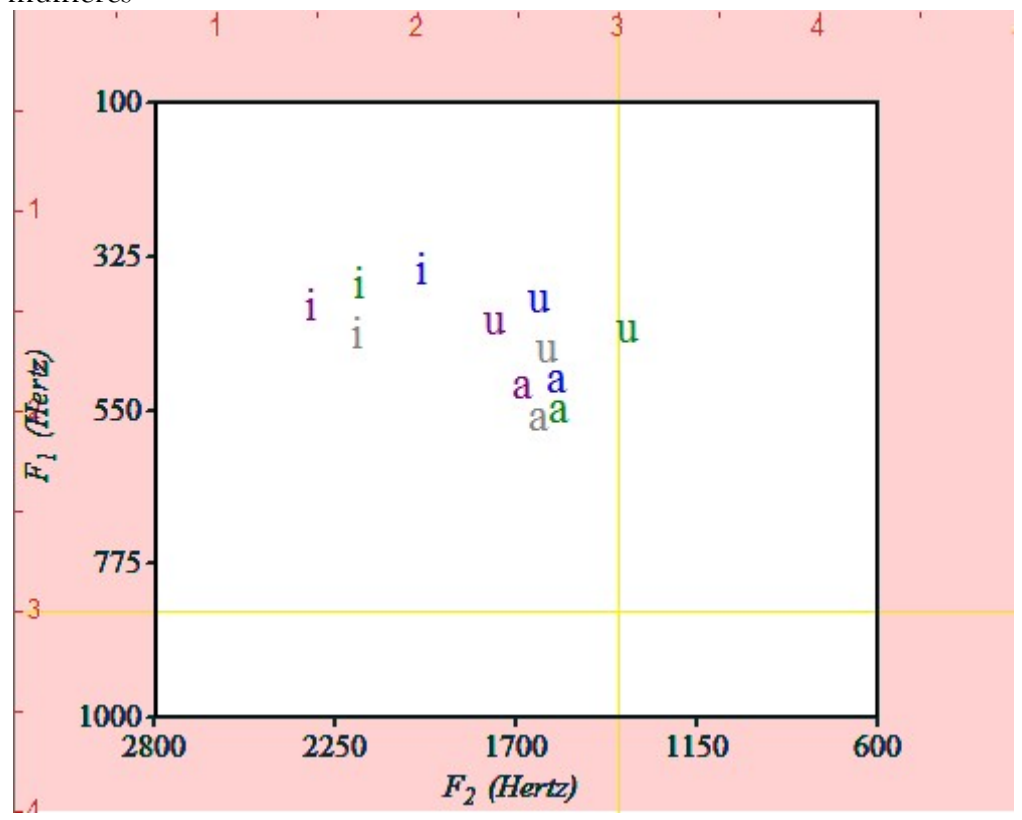

Nos gráficos de dispersão apresentados do grupo de homens e mulheres, percebe-se que as vogais postônicas [i] e [u] tendem a abaixar enquanto a vogal [a] tende a elevar-se. Além disso, percebe-se uma centralização de [u], passando a ocupar, entre os homens, quase o mesmo espaço acústico que a vogal [a].

É importante destacar que as vogais postônicas se realizam de diferentes maneiras, provavelmente em função do contexto seguinte, o que pode ocasionar a não diferenciação da produção de [a] em relação à produção de $[\mathrm{u}]$ em certos contextos.

De acordo com Steves e House (1955), em posição átona final as vogais estão propensas a realizarem-se como uma vogal neutra, já que há o relaxamento dos articuladores. Sendo assim, como consequência, os valores concentram-se na região central do espaço acústico F1 X F2, podendo haver sobreposição de valores. 


\section{Considerações finais}

Buscou-se, com este trabalho, contribuir para a caracterização acústica das vogais presentes no falar pelotense em posição átona final. De modo geral, percebe-se que as vogais postônicas [i] e [u] tendem a abaixar enquanto a vogal [a] tende a elevar-se.

Além disso, percebe-se uma centralização de [u], que passa a ocupar, entre os homens, quase o mesmo espaço acústico que a vogal [a]. Isso significa que o sistema postônico encontrado nessa amostra seria mais bem representado pelas vogais [e], [I] e [U].

Em relação à duração da postônica, verificou-se que entre os homens de baixa escolaridade, as vogais [e], [I] e [U] foram produzidas de forma significativamente mais longa do que entre os homens de alta escolaridade. Já no grupo das mulheres, a vogal $[\mathfrak{e}]$ apresentou duração significativamente mais longa entre aquelas que possuem alta escolaridade do que entre as de baixa escolaridade.

\section{REFERÊNCIAS}

BARBOSA, P. A.; MADUREIRA, S. Manual de fonética acústica experimental: aplicações a dados do português. São Paulo: Cortez, 2015.

DIAS, E.; SEARA, I. Redução e Apagamento de Vogais Átonas Finais na Fala De Crianças e Adultos de Florianópolis: Uma Análise Acústica. Letrônica, Porto Alegre, v. 6, n. 1, 2013, p. 71-93.

ESCUdero, P., BOERSMA, P., RAUber, A. S., BION, R. A. H. A cross-dialect acoustic description of vowels: Brazilian and European Portuguese. Journal of the Acoustical Society of America, 126(3), 1379. 1393, 2009.

MENESES, F. O. As vogais desvozeadas no português brasileiro: investigação acústico-articulatória. 101f. Dissertação (Mestrado em Linguística) Instituto de Estudos da Linguagem, Universidade Estadual de Campinas, Campinas, 2012.

- Uma visão dinâmica dos processos de apagamento de vogais no português brasileiro. 140f. Tese (Doutorado). Instituto de Estudos da Linguagem, Universidade Estadual de Campinas, 2016. 
$84 \mid$ Fernanda Peres Lopes e Maria José Blaskovski Vieira

MORAES, J; Y. LEITE; D. CALLOU. Caracterização Acústica das Vogais Tônicas do Português Culto. In: M. Kato (org.) Gramática do Português Falado. Vol. V: Convergências. 2 ed. Campinas: Editora da Unicamp, 2002.

QUINTANILHA-AZEVEDO, R. Formalização fonética-fonológica da interação de restrições na produção e na percepção da epêntese no português brasileiro e no português europeu. 286f. Tese (Doutorado em Linguística) - Programa de Pós-Graduação em Letras, Universidade Católica de Pelotas, Pelotas, 2016.

STEVES, K. N; HOUSE, Arthur S. Development of a quantitative description of vowel articulation. The Journal of the Acoustical Society of America, v. 27, n. 3, p. 484-493, mai. 1955.

Recebido em: 01/04/2019

Aceito em: 09/04/2019 